\title{
REVIEW
}

\section{Clinical review: Exogenous surfactant therapy for acute lung injury/acute respiratory distress syndrome - where do we go from here?}

\author{
Ahilanandan Dushianthan*1,2, Rebecca Cusack1, Victoria Goss², Anthony D Postle² and Mike PW Grocott1,2
}

\begin{abstract}
Acute lung injury and acute respiratory distress syndrome (ARDS) are characterised by severe hypoxemic respiratory failure and poor lung compliance. Despite advances in clinical management, morbidity and mortality remains high. Supportive measures including protective lung ventilation confer a survival advantage in patients with ARDS, but management is otherwise limited by the lack of effective pharmacological therapies. Surfactant dysfunction with quantitative and qualitative abnormalities of both phospholipids and proteins are characteristic of patients with ARDS. Exogenous surfactant replacement in animal models of ARDS and neonatal respiratory distress syndrome shows consistent improvements in gas exchange and survival. However, whilst some adult studies have shown improved oxygenation, no survival benefit has been demonstrated to date. This lack of clinical efficacy may be related to disease heterogeneity (where treatment responders may be obscured by nonresponders), limited understanding of surfactant biology in patients or an absence of therapeutic effect in this population. Crucially, the mechanism of lung injury in neonates is different from that in ARDS: surfactant inhibition by plasma constituents is a typical feature of ARDS, whereas the primary pathology in neonates is the deficiency of surfactant material due to reduced synthesis. Absence of phenotypic characterisation of patients, the lack of an ideal natural surfactant material with adequate surfactant proteins, coupled with uncertainty about optimal timing, dosing and delivery method are some of the limitations of published surfactant replacement clinical trials. Recent advances in stable isotope labelling of surfactant phospholipids coupled with analytical methods using electrospray ionisation mass spectrometry enable highly specific molecular assessment of phospholipid subclasses and synthetic rates that can be utilised for phenotypic characterisation and individualisation of exogenous surfactant replacement therapy. Exploring the clinical benefit of such an approach should be a priority for future ARDS research.
\end{abstract}

\section{Introduction}

Acute respiratory distress syndrome (ARDS), first described by Ashbaugh and colleagues in 1967 [1], is a leading cause of morbidity and mortality in critically ill patients. Outside clinical trial settings, mortality still remains as high as 50\% [2]. Diffuse alveolar damage is a typical histopathological feature of ARDS [3]. Three sequential pathological stages of exudation, cellular proliferation and fibrosis are commonly recognised. In the early exudative phase, alveolar epithelial and endothelial injury lead to the accumulation of protein-rich

*Correspondence: adushianthan@gmail.com

${ }^{1}$ Anaesthesia and Critical Care Research Unit, CE 93, MP24, E-Level, Centre Block, University Hospital Southampton NHS Foundation Trust, Southampton SO16 6YD, UK

Full list of author information is available at the end of the article pulmonary oedema. This phase is followed by varying degrees of type II cell proliferation, accumulation of fibroblasts and myofibroblasts associated with collagen deposition in the extracellular matrix, and in some patients this leads to fibrosis [3]. The clinical consequences of the initial injury are refractory hypoxemia and poor lung compliance necessitating mechanical ventilatory support. The diagnostic criteria established by the American-European Consensus Conference in 1994 encompass simple physiological, laboratory and radiological variables [4] but are limited by low specificity and substantial interobserver variability $[5,6]$. According to these criteria, ARDS is diagnosed by $\mathrm{PaO}_{2} / \mathrm{FiO}_{2}$ ratio $\leq 200 \mathrm{mmHg}$ with bilateral infiltrates on chest radiograph in the absence of raised left atrial hypertension. Acute lung injury (ALI) is defined by the same criteria as ARDS, but with a lesser degree of hypoxemia $\left(\mathrm{PaO}_{2} / \mathrm{FiO}_{2}\right.$ $\leq 300 \mathrm{mmHg}$ ) [4]. 
ARDS/ALI may result from both direct lung injury (for example, pneumonia, aspiration, drowning and toxic inhalation) and indirect lung injury (for example, sepsis, trauma, blood transfusion and pancreatitis) [3], causing significant phenotypic heterogeneity among patients. Variability in both patients and pathology may explain the disappointing results from many ARDS clinical trials. Indeed, some authors question whether it is reasonable to cohort such varied pathologies within a single unifying diagnostic syndrome [7]. An expert consensus panel has recently proposed a new diagnostic definition (Berlin Definition of ARDS) [8], which subgroups patients according to disease severity defined by the degree of hypoxemia: mild $\left(\mathrm{PaO}_{2} / \mathrm{FiO}_{2} \leq 300 \mathrm{mmHg}\right)$; moderate $\left(\mathrm{PaO}_{2} /\right.$ $\left.\mathrm{FiO}_{2} \leq 200 \mathrm{mmHg}\right)$; and severe $\left(\mathrm{PaO}_{2} / \mathrm{FiO}_{2} \leq 100 \mathrm{mmHg}\right)$. While this definition may facilitate a stratified treatment approach based on severity of hypoxemia, it does not take into account the clinical heterogeneity related to mechanism of injury [8].

Although surfactant alterations are implicated in the pathogenesis of ARDS, surfactant replacement remains of unproven benefit in adult patients. A number of issues relating to human surfactant biology and ARDS may have implications for the design of future surfactant replacement clinical trials and therefore merit closer scrutiny.

\section{Human surfactant system in health}

The complex mammalian ventilatory system is primarily dependent on surfactant to stabilise alveolar air sacs during respiration. Surfactant is a complex mixture of lipoproteins synthesised, secreted and recycled by type II alveolar cells. Phospholipids make up most of the lipid component of surfactant, but lower levels of neutral lipids such as cholesterol also present. Phosphatidylcholine (PC) is the dominant phospholipid subclass accounting for $\sim 70 \%$ of pulmonary surfactant, with phosphatidylglycerol and to a lesser extent phosphatidylethanolamine, phosphatidylinositol, phosphatidylserine and sphingomyelin accounting for the rest [9] (Table 1). PC16:0/16:0 (dipalmitoyl phosphatidylcholine (DPPC)) is the most abundant PC molecule and has unique characteristics of alveolar surface tension reduction in humans [10]. Other PC species - notably PC16:0/18:2, PC16:0/16:1, PC16:0/14:0 and PC16:0/18:2 make up the majority of the rest of surfactant PC composition [11] (Table 2). The relative proportions of these PC species differ among mammalian species, suggesting the possibility of functional variation [12].

Four surfactant proteins have so far been identified (SP-A to SP-D). SP-B and SP-C are hydrophobic proteins, and their primary function is to facilitate the surface tension-reducing characteristics of surfactant phospholipids. SP-A and SP-D are hydrophilic collectin proteins, which are involved in the innate immunity. They have
Table 1. Phospholipid composition of the human surfactant system [9]

\begin{tabular}{lc}
\hline Phospholipid subclass & $\begin{array}{c}\text { Composition (\% of total } \\
\text { phospholipid) }\end{array}$ \\
\hline Phosphatidylcholine & 68 \\
Phosphatidylglycerol & 10 \\
Phosphatidylethanolamine & 5 \\
Phosphatidylinositol & 4 \\
Phosphatidylserine & 2 \\
Sphingomyelin & 4 \\
\hline
\end{tabular}

Table 2. Molecular phosphatidylcholine composition of the human surfactant system [11]

\begin{tabular}{lc}
\hline PC species & Composition (\% of total PC) \\
\hline PC16:0/14:0 & 7.2 \\
PC16:0/16:1 & 4.8 \\
PC16:0/16:0 & 60.6 \\
PC16:0/18:2 & 5.4 \\
PC16:0/18:1 & 9.7 \\
PC16:0/20:4 & 1.9 \\
PC18:0/18:2 & 1.5 \\
PC18:1/18:1 & 3.2 \\
$P C 18: 0 / 18: 1$ & 2.1 \\
\hline
\end{tabular}

PC, phosphatidylcholine.

collagen-like domains, which are pattern recognition molecules that facilitate the interaction and removal of a variety of microorganisms and antigens [13].

\section{Surfactant abnormalities in ARDS}

Earlier postmortem studies have suggested a defective surfactant with reduced surface-lowering characteristics might be contributing to the development of ARDS $[1,14]$. A number of studies since then have assessed the compositional changes in surfactant from bronchoalveolar lavage fluid (BALF) of patients with ARDS [11, 15-20]. Despite substantial variation in patient characteristics and study methodology, consistent changes in surfactant composition are apparent in these patients (Table 3).

\section{Total phospholipid concentration}

Determining total phospholipid concentrations in the alveolar surfactant pool is difficult and depends on many factors including the lavage technique, the surface area lavaged and the amount of lavage fluid recovered. These technical issues are reflected in the variability of the results in published clinical studies. An early study by Hallman and colleagues showed normal surfactant phospholipid concentrations in patients with ARDS [15]. However, subsequent studies have shown consistently 
Table 3. Surfactant abnormalities seen in clinical studies of ARDS/ALI patients

\begin{tabular}{ll}
\hline Surfactant characteristic & Abnormalities in ALI/ARDS \\
\hline Surface activity & Reduced surface tension \\
Phospholipid profile & $\begin{array}{l}\text { Reduced levels and fractional concentrations of phosphatidylcholine and phosphatidylglycerol with increase in } \\
\text { fractional concentrations of phosphatidylinositol, phosphatidylethanolamine, phosphatidylserine and } \\
\text { sphingomyelin }\end{array}$ \\
Phosphatidylcholine composition & $\begin{array}{l}\text { Reduced levels and fractional concentrations of dipalmitoyl phosphatidylcholine with increased fractional } \\
\text { concentration of unsaturated species }\end{array}$ \\
Surfactant aggregates & Reduced proportion of large aggregates to small aggregates \\
Surfactant proteins & Decreased alveolar surfactant proteins and increased plasma surfactant proteins \\
\hline
\end{tabular}

ALI, acute lung injury; ARDS, acute respiratory distress syndrome.

lower total BALF surfactant phospholipid concentrations in patients with ARDS [16,17], particularly in those where the precipitating cause was pneumonia [17].

\section{Phospholipid and phosphatidylcholine composition}

The surfactant phospholipid composition in ARDS is characterised by a relative decrease in the fractional concentrations of PC and phosphatidylglycerol with an increase in phosphatidylinositol, phosphatidylethanolamine and phosphatidylserine. The assessment of surfactant composition has been limited by the analytical methods available to quantify PC composition, which have lacked precision in identifying molecular species. Two methodological limitations are particularly important. First, quantifying total disaturated $\mathrm{PC}$ as a surrogate for DPPC using osmium tetroxide $[15,21]$ has an inherent limitation because this technique also measures other disaturated molecular species such as PC16:0/14:0. Second, assessment of the relative content of individual fatty acids by chromatographic techniques does not reveal the specific molecular structure of individual surfactant PC components [20]. When high-performance liquid chromatography (HPLC) was used to analyse specific molecular PC species in a study of BALF from patients with ARDS, lower concentrations of DPPC and increases in other unsaturated PC species - particularly PC16:0/18:1, PC16:0/18:2, PC18:0/18:2 and PC16:0/20:4 were demonstrated [11].

\section{Surfactant protein concentration}

There is an increased total protein concentration in BALF of patients with ARDS $[11,18]$. This is coupled with a reduction in surfactant-associated proteins SP-A, SP-B and SP-C $[11,22]$. SP-D concentrations in BALF may remain relatively unchanged during the disease process [22].

\section{Surfactant aggregates}

Large surfactant aggregates composed of lamellar bodies, tubular myelin and large multilamellar vesicles are highly surface active [23]. During surfactant turnover prior to endocytosis these large aggregates are converted to inactive small aggregates composed of unilamellar vesicles. The exact mechanism leading to this conversion is not fully understood. Reduction in large surfactant aggregates with a relative increase in small aggregates is characteristic of surfactant from patients with ARDS $[11,17]$. Reduced levels of large surfactant aggregates are also associated with low survival rates [11].

\section{Possible mechanisms underlying compositional alterations and dysfunctional surfactant in ARDS}

The pathogenesis of surfactant changes in ARDS is poorly understood. Although several animal lung injury models have been utilised, the relevance and applicability of these models in human ARDS remain uncertain. Translation from animal and in vitro models of surfactant dysfunction suggests the possibility of several pathological mechanisms causing surfactant compositional and functional alterations during lung injury. These include reduced surfactant synthesis by injured type II cells, surfactant functional inhibition by plasma constituents, and increased breakdown by activated oxidative and hydrolytic pathways (Table 4). Each of these mechanisms probably contributes to surfactant dysfunction to varying degrees in individual patients.

\section{Synthetic dysfunction}

In ARDS, synthetic or secretory dysfunction may result from direct or indirect injury to alveolar type II cells. Animal models of hyperoxia-induced direct lung injury show decreased surfactant PC synthesis [24]. In contrast, subcutaneous injection of nitrogenated urethane compound ( $N$-nitroso- $N$-methyl-urethane), which is toxic to type II cells, leads to increased surfactant saturated PC synthesis and secretion [25]. This paradoxical finding highlights the limitations of animal lung injury models and may be due to the different mechanisms of injury in these studies.

Stable isotope labelling of surfactant precursors is a novel approach to study surfactant kinetics in humans [26]. One in vivo study using such a method suggests 
Table 4. Possible reasons for surfactant abnormalities in acute respiratory distress syndrome/acute lung injury

Reduced surfactant synthesis and recycling by injured type II cells

Increased breakdown by hydrolysis and proteolysis

Oxidative injury by reactive oxygen species

Dilution of surfactant material by florid oedema/fluid

Dysfunctional surfactant film formation due to accumulation of plasma constituents

Inhibition by competitive adsorption of plasma proteins

there is an increased surfactant PC synthesis in ARDS patients compared with ventilated controls [27]. In contrast to this, sequential quantitative BALF studies in ARDS patients have shown consistently lower concentrations of PC [18] and DPPC [11]. Surfactant SP-D is primarily secreted by type II cells and can be used as a surrogate biomarker for alveolar epithelial injury [28]. Although BALF SP-D levels remain relatively unchanged during the disease course, lower SP-D levels are evident in a subgroup of ARDS patients and are associated with a significant increase in mortality [22]. Variation in the volume of BALF recovery may in part explain these findings. Another possible explanation is variable surfactant synthetic and secretory patterns amongst patients with similar clinical pictures: in other words, phenotypic variation that can only be identified through in vivo characterisation of surfactant metabolism.

\section{Surfactant functional inhibition}

During the early stages of ARDS, there is flooding of plasma material (plasma proteins, red blood cells, fibrin and fibrin degradation products) into the alveolar space due to endothelial and epithelial injury. In experimental models, plasma proteins - in particular, albumin, haemoglobin, fibrinogen and fibrin monomers have been shown to impair surfactant function and hence increase surface tension [29]. Reconstitution of protein extracted from BALF supernatant resulted in further deterioration of surface tension, suggesting an inhibitory effect of leaked plasma proteins within the alveolar space [17]. Although the exact mechanisms of surfactant functional inhibition by plasma constituents are not well established, competitive adsorption of plasma proteins [29] and dysfunctional surfactant film formation [30] have both been postulated.

\section{Increased surfactant breakdown by oxidation}

Reactive oxygen species are generated as a part of normal oxygen metabolism and are physiologically active in cell signalling. Various reactive oxygen species, including hydrogen peroxide, superoxide and nitric oxide, are released by enzymatic reactions (xanthine oxidase/glucose oxidase/nicotinamide adenine dinucleotide phosphate oxidase) from inflammatory cells. Oxidative disruption of lipids and proteins leads to dysfunctional surfactant and this has been postulated as contributory to the pathogenesis of lung injury [31]. Exogenous surfactant is also subject to reactive oxygen species mediated oxidation, leading to diminished surface tension-reducing characteristics [32].

\section{Increased surfactant breakdown by hydrolysis}

Secretory phospholipase $\mathrm{A}_{2}$ (PLA P $_{2}$ activity is increased in BALF from patients with ARDS [33]. PLA $\mathrm{P}_{2}$-mediated hydrolysis of surfactant phospholipids contributes directly to surfactant dysfunction and generates free fatty acids that further inhibit surfactant function [34,35]. Hydrolysis of surfactant PC leads to lysophosphatidylcholine formation, and higher levels of $\mathrm{PLA}_{2}$ activity and lysophosphatidylcholine concentration in ARDS are associated with increased mortality $[33,36]$.

\section{Surfactant replacement in ARDS/ALI}

Fujiwara and colleagues reported the first positive, uncontrolled, clinical study of surfactant replacement in 1980 [37]. In this study, 10 premature neonates with severe respiratory distress syndrome were successfully treated with natural bovine surfactant supplemented with synthetic DPPC and phosphatidylglycerol. Subsequent randomised clinical trials (RCTs) with both natural and synthetic surfactant preparations have shown consistent improvements in lung mechanics, oxygenation and mortality in neonatal respiratory distress syndrome [38].

Several RCTs of surfactant replacement in adults with ARDS have been conducted since 1994 [39-46]. These generally have shown improvements in oxygenation indices but have failed to produce any demonstrable survival benefits [47].

An initial phase I study of synthetic surfactant composed of DPPC without any surfactant proteins (Exosurf) demonstrated its safety profile in 51 patients with sepsisinduced ARDS [39]. In this study, surfactant was nebulised for 5 days continuously and a trend towards mortality benefit was seen in the treatment group. A subsequent larger RCT using the same methods with the same surfactant preparation and study population failed to show any benefits in oxygenation, mortality, length of ICU stay or duration of mechanical ventilation [40]. These negative results may be explained by the lack of surfactant proteins in the surfactant preparation leading to reduced surface spreading characteristics and poor alveolar surfactant deposition by this delivery method (estimated only $5 \%$ deposition) [40].

Gregory and colleagues performed a phase II RCT using bovine lung extract containing phospholipids, neutral lipids, fatty acids and surfactant proteins SP-B and SP-C in patients with ARDS. This study enrolled 59 
patients and demonstrated improved oxygenation and a trend towards reduced mortality in the surfactant group [41].

A European-based multicentre RCT using a large bolus tracheal instillation of freeze-dried natural porcine surfactant (HL-10) failed to show any mortality benefit. This surfactant preparation consisting of phospholipids (90 to 95\%) and SP-B and SP-C (1 to 2\%) was instilled for up to three doses (totalling $600 \mathrm{mg} / \mathrm{kg}$ ). This study of 418 ARDS/ALI patients was terminated early due to an excess of serious adverse events, such as hypotension and hypoxemia, in the treatment group [42].

Spragg and colleagues conducted three RCTs with a surfactant preparation consisting of phospholipids and recombinant SP-C. Following positive results from an animal study [48], a phase II study of recombinant SP-C in 40 ARDS patients showed a good safety profile [43]. This study was followed by a large multicentre phase III RCT of 448 ARDS patients, which showed improved oxygenation but no overall mortality benefit in the treatment group [44]. However, post hoc analysis demonstrated a trend towards mortality benefit for those patients with direct lung injury from aspiration and pneumonia [44]. Following this study, a further phase III RCT was conducted in a large cohort of patients $(844$ patients) with severe hypoxemia secondary to aspiration and pneumonia. There was no mortality benefit and the study was terminated early due to futility. Furthermore, contrary to the results of previous studies, this study reported a lack of improvement in oxygenation and increased treatment-related serious adverse events [46]. In this study, however, the surfactant preparation process involved a shearing step where it was passed forcefully through a narrow channel to improve suspension and distribution. This shearing step may have resulted in reduced surface tension-lowering properties by possibly exposing the exogenous surfactant to functional inhibition by plasma proteins [46].

Improved gas exchange was noted in nonrandomised clinical studies with bronchoscopic administration of natural porcine surfactant [49] and bovine surfactant $[50,51]$. However, these studies were small, noncontrolled and their findings have not been replicated in larger randomised controlled studies.

\section{Possible explanations for the negative results from surfactant replacement studies in ARDS}

No large RCT of exogenous surfactant replacement has shown reduced mortality from this intervention (Table 5). This finding has been confirmed by a recent systematic review and meta-analysis that included nine RCTs with a total of 2,575 patients, which found no evidence of a mortality benefit. However, the validity of this result is limited by the substantial clinical heterogeneity of the studies included in this analysis [47]. Possible reasons for this failure of a theoretically promising therapy include the differences in the exogenous surfactant composition, drug delivery methods and the presence of variation in surfactant biology among the target population.

\section{Exogenous surfactant composition}

Surfactant preparations vary according to their composition, biophysical activity, susceptibility to functional inhibition, preparation technique and associated costs. The relative composition of DPPC and surfactant proteins influences surface tension-lowering characteristics of the exogenous surfactant. Although DPPC is the primary surface tension-lowering molecule, pure DPPC preparations are limited by their lack of surface spreading and adsorption characteristics $[39,40]$.

Although recent studies with recombinant SP-C-based surfactant preparation showed no mortality benefit $[44,46]$, manipulation of the composition by adding other surfactant proteins may potentiate its clinical effect. For instance, SP-A has been shown to improve phospholipid adsorption and surface activity and may reduce conversion of large to small aggregates [52,53]. Developing surfactant preparations that more closely reflect natural human surfactant in the alveolus may therefore improve clinical outcome. In the neonatal population, natural surfactants from lavage or homogenised lung are clinically more effective than synthetic preparations [54]. However, compared to neonates, a large amount of exogenous surfactant is needed to provide adequate treatment in adults. Furthermore, replacement strategies using natural surfactant preparations are costly due to the laborious extraction techniques.

\section{Surfactant delivery methods}

Clinical studies with nebulised surfactant preparations conducted in the 1990s were limited by poor alveolar deposition $[39,40]$. Much of the published work since then has evaluated surfactant delivery via intratracheal instillation [41-46]. A large quantity of surfactant material is generally delivered by this route, which may be of benefit in counteracting the effect of surfactant inhibition [42]. However, this large quantity delivery can result in flooding of the central airways and lead to increased airway resistance and worsening of hypoxemia. In animal models, intratracheal administration leads to poor surfactant deposition in the collapsed alveoli [55]. An alternative is sequential bronchoscopic administration, which has been evaluated in a number of uncontrolled studies. Bronchoscopic sequential segmental administration of natural bovine surfactant was associated with improved $\mathrm{PaO}_{2} / \mathrm{FiO}_{2}$ ratios coupled with improved ventilation-perfusion matching in the lungs [50], as well 
Table 5. Characteristics of surfactant replacement RCTs in ARDS/ALI

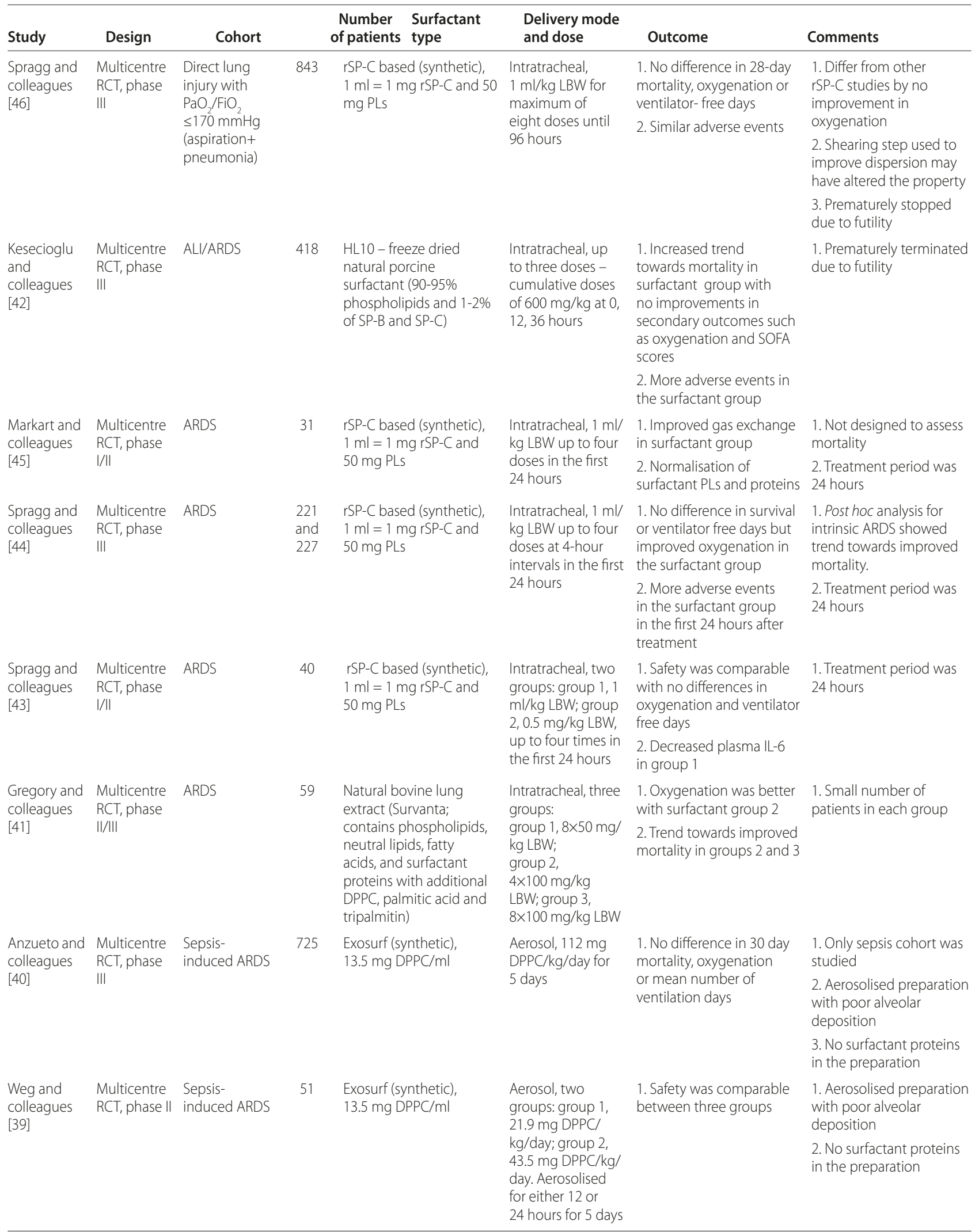

$\mathrm{ALI}$, acute lung injury; ARDS, acute respiratory distress syndrome; DPPC, dipalmitoyl phosphatidylcholine; IL, interleukin; LBW, lean body weight; PL, phospholipid; $\mathrm{RCT}$, randomised controlled trial; rSP-C, recombinant surfactant protein C; SOFA, Sequential Organ Failure Assessment score. 
as relative normalisation of surfactant composition and function [51]. However, this technique is time consuming and resource intensive and may not be feasible in clinical practice or large RCTs.

Uniform delivery of surfactant material to both affected and unaffected parts of the lung might improve atelectasis in affected areas, but may be detrimental in unaffected areas. Computerised tomography has demonstrated the heterogeneous distribution of lung injury in ARDS, with the lower zones of the lungs tending to be most affected [56]. Computerised tomography images may help to guide targeted bronchoscopic administration of exogenous surfactant to affected lobes.

\section{Clinical heterogeneity of surfactant biology in ARDS}

ARDS encompasses a variety of aetiologies leading to an apparently common diffuse alveolar damage. Consequently, surfactant alterations are attributed to several pathological mechanisms, which have not been fully explored by human studies. Specifically, patterns of surfactant synthesis and metabolism have not been characterised in ARDS. Current ARDS diagnostic definitions are uninformative with regards to the degree of alveolar injury, the dynamic surfactant pool and surfactant metabolism. Phenotypic characterisation of groups with surfactant synthetic dysfunction may help to target those patients most likely to benefit from exogenous surfactant replacement. For example, reduced surfactant synthesis in neonatal respiratory distress syndrome provides the best human surfactant-deficient lung injury model - and in this context, exogenous surfactant replacement leads to reduced morbidity and mortality [38].

Where there is intact alveolar synthetic function, assessment of the degree of surfactant inhibition or breakdown by hydrolysis and oxidation may be of value. Testing of patient's endogenous surfactant against the exogenous surfactant material may provide important clues to the degree of functional inhibition that may be encountered during supplementation. Attempts to counteract this by instilling large amounts of exogenous surfactant may result in an increased risk of serious adverse events [42]. Addition of other surfactant proteins such as SP-A or SP-B may counteract functional inhibition by plasma constituents and has been shown to improve the efficacy of exogenous surfactant preparations in in vitro studies $[57,58]$.

The combination of increased PLA 2 activity in BALF and increased concentrations of lysophospholipids may serve as markers of phospholipase-mediated surfactant phospholipid breakdown. This breakdown could be counteracted by PLA ${ }_{2}$-resistant surfactant analogues such as phospholipase-resistant diether lipids [59], PLA ${ }_{2}$ inhibitors or SP-A [60].

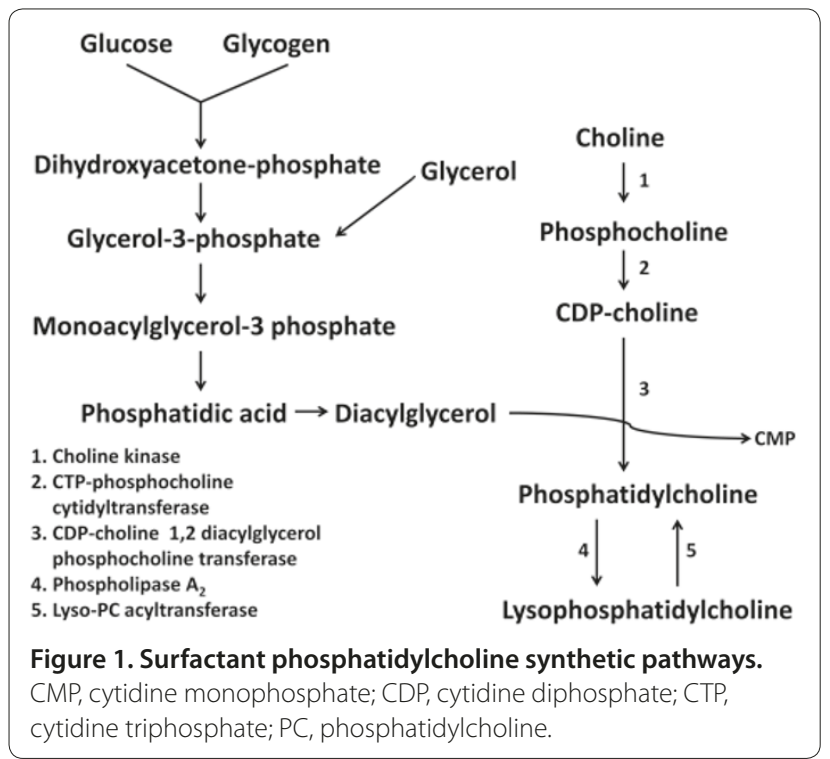

Exogenous surfactant subjected to oxidation has reduced surface activity [61,62] and this may have contributed to the negative clinical outcomes in ARDS trials. Oxidative metabolites of phospholipids can be quantified by mass spectrometry [63]. These oxidised phospholipids may be used as a surrogate to assess the degree of oxidation mediated surfactant breakdown. The potential of oxidised phospholipids as biomarkers in this context has not been fully explored. SP-A and SP-D have antioxidant activity [64] and augmentation of these proteins or other endogenous antioxidants such as superoxide dismutase, vitamin E, melatonin and ebselen may moderate oxidative breakdown of exogenous surfactant in those with high levels of surfactant oxidation [65].

\section{Can we phenotype patients according to surfactant synthetic function?}

Clinical trials of exogenous surfactant have not so far phenotyped patients according to alveolar surfactant synthesis, metabolism and degree of functional inhibition prior to replacement strategies. Improved characterisation of synthetic ability and surfactant function may identify selected patient groups that may benefit from specific surfactant therapies individualised according to the underlying pathophysiological processes.

In patients with ARDS, dynamic surfactant assessment involves consecutive BALF analyses to demonstrate timedependent changes in surfactant composition [11,22]. These studies have inherent limitations, including variable BALF recovery and lack of information regarding synthesis or turnover. Radio-isotope-labelling studies conducted in previous decades provided substantial knowledge regarding the nature of surfactant dynamics in animal models of lung injury, but these techniques are 


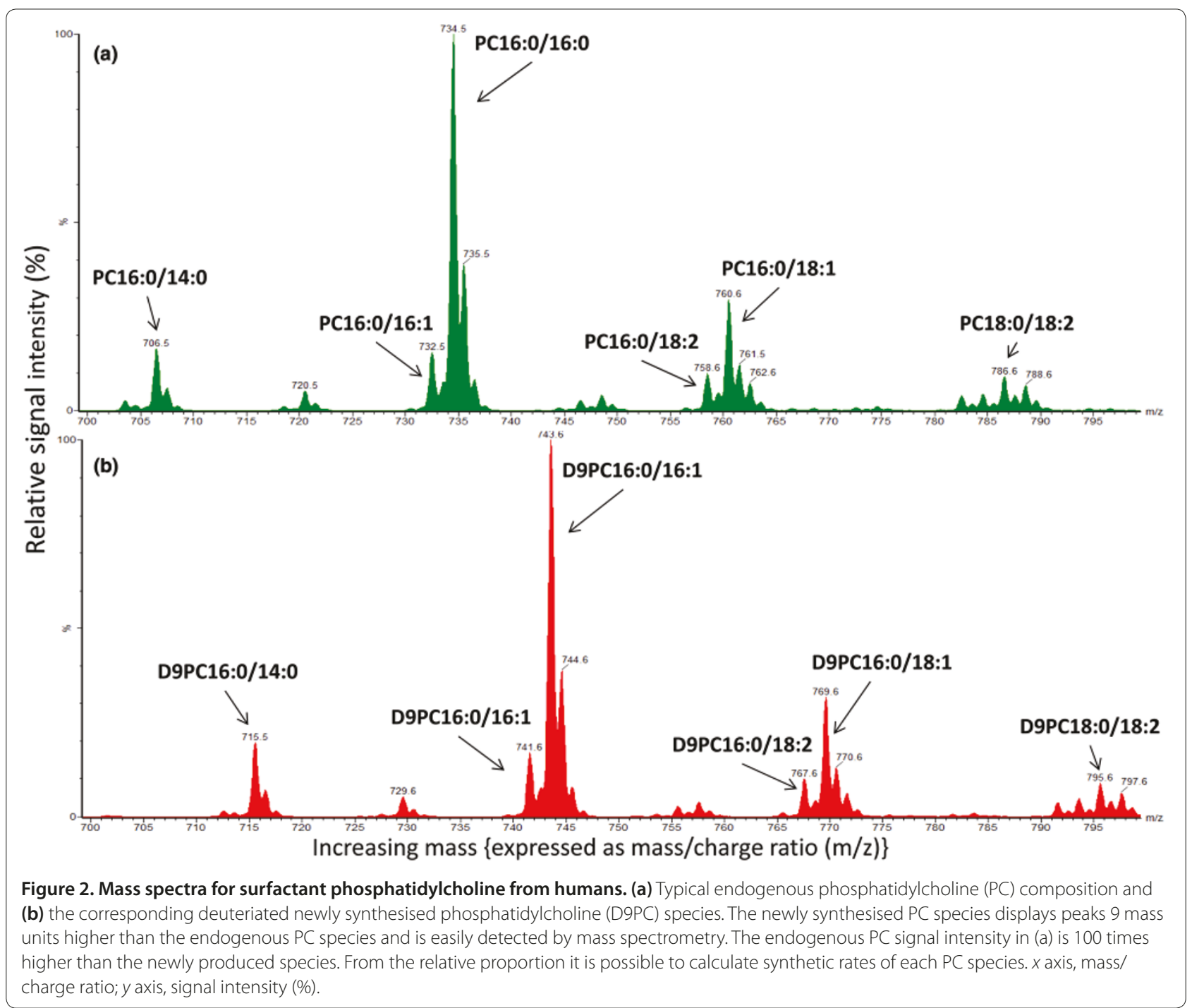

not applicable to the study of humans. Surfactant PC is synthesised from phospholipid precursors such as glucose, glycerol and choline via the cytidine diphosphate-choline pathway (Figure 1). By labelling these phospholipid precursors with stable (nonradioactive) isotopes, it is possible to assess surfactant PC synthetic rates and metabolism. ${ }^{13} \mathrm{C}$-labelled glucose and free fatty acids, such as labelled ${ }^{13} \mathrm{C}$-palmitic acid (16:0), have been used successfully to study surfactant metabolism in neonates [66]. The fractional synthetic rates (percentage of newly synthesised surfactant per day) of disaturated surfactant PC (Palmitate 16:0) can be quantified using gas chromatography-isotope ratio mass spectrometry (GC-IRMS) by the detection of incorporated labelled ${ }^{13} \mathrm{C}$. However, fatty acid labelling only provides information regarding metabolism of that particular fatty acid in question and the assessment of ${ }^{13} \mathrm{C}$ enrichment using GC-IRMS is not informative for the synthesis and metabolism of other individual surfactant PC species [26].

An alternative technique is the use of deuterium, which is a naturally occurring stable isotope of hydrogen. Isotope labelling of choline with nine deuterium atoms, which increases the number of mass units by +9 in the PC head group in subsequent metabolic products, helps to trace specific PC molecular species in pulmonary surfactant. Advances in analytical techniques with the evolution of electrospray ionisation mass spectrometry now allow identification of each species of surfactant PC with high sensitivity using specified scans. Figure 2 shows typical mass spectra for native surfactant $\mathrm{PC}$ composition (Figure 2a) and the newly produced deuteriated PC species (Figure 2b). Using this methodology, deuteriated choline incorporation into sputum PC has been assessed in healthy volunteers, demonstrating the feasibility of measuring synthetic rates of individual surfactant PC 
species [67]. Further studies are needed to evaluate this technique in the alveolar surfactant pool in health and disease states such as ARDS.

\section{Conclusion}

Knowledge of surfactant biology has evolved over the last 50 years, providing valuable insight into alveolar surfactant physiology in lung injury. However, there remain substantial knowledge gaps that need to be addressed by future research. An ideal surfactant material that mimics the properties of human surfactant is lacking and research should focus on refining surfactant preparations that incorporate all surfactant proteins as well as developing measures to reduce the impact of functional inhibition. Targeting of surfactant delivery to the lobes that are most affected may also be of benefit. Finally, and most crucially, the target population needs to be characterised according to surfactant synthetic function using the best available technology, including nonradioisotope labelling of surfactant precursors. This characterisation may permit stratification of the ALI/ ARDS population according to the surfactant synthetic capability of alveolar type II cells and provide a rational basis for targeting exogenous surfactant interventions.

\section{Abbreviations \\ $A L I$, acute lung injury; ARDS, acute respiratory distress syndrome; BALF, bronchoalveolar lavage fluid; DPPC, dipalmitoyl phosphatidylcholine; $\mathrm{FiO}_{2}$, proportion of oxygen in the inhaled air; HPLC, high-performance liquid chromatography; $\mathrm{PaO}_{2}$, partial pressure of arterial oxygen; $\mathrm{PC}$, phosphatidylcholine; PLA, phospholipase $A_{2} ; R C T$, randomised controlled trial; SP, surfactant protein. \\ Competing interests \\ ADP has no direct financial interest in the work presented in this review; his surfactant research programme is supported by kind donation of a therapeutic surfactant from Chiesi for a clinical trial. The remaining authors declare that they have no competing interests.}

\section{Acknowledgements}

All authors are funded in part by the University Hospitals Southampton NHS Foundation Trust - University of Southampton Respiratory Biomedical Research Unit which received a portion of its funding from the United Kingdom Department of Health's National Institute of Health Research Biomedical Research Unit funding scheme.

\section{Author details}

'Anaesthesia and Critical Care Research Unit, CE 93, MP24, E-Level, Centre Block, University Hospital Southampton NHS Foundation Trust, Southampton SO16 6YD, UK. ${ }^{2}$ Integrative Physiology and Critical IIIness, Clinical and Experimental Sciences, Faculty of Medicine, University of Southampton, University Hospital Southampton NHS Foundation Trust, Southampton SO16 6YD, UK.

Published: 22 November 2012

\section{References}

1. Ashbaugh DG, Bigelow DB, Petty TL, Levine BE: Acute respiratory distress in adults. Lancet 1967, 2:319-323.

2. Villar J, Blanco J, Añón JM, Santos-Bouza A, Blanch L, Ambrós A, Gandía F, Carriedo D, Mosteiro F, Basaldúa S, Fernández RL, Kacmarek RM; ALIEN Network: The ALIEN study: incidence and outcome of acute respiratory distress syndrome in the era of lung protective ventilation. Intensive Care
Med 2011, 37:1932-1941.

3. Ware LB, Matthay MA: The acute respiratory distress syndrome. N Engl J Med 2000, 342:1334-1349.

4. Bernard GR, Artigas A, Brigham KL, Carlet J, Falke K, Hudson L, Lamy M, Legall JR, Morris A, Spragg R: The American-European Consensus Conference on ARDS. Definitions, mechanisms, relevant outcomes, and clinical trial coordination. Am J Respir Crit Care Med 1994, 149:818-824.

5. Ferguson ND, Frutos-Vivar F, Esteban A, Fernandez-Segoviano P, Aramburu JA, Najera L, Stewart TE: Acute respiratory distress syndrome: underrecognition by clinicians and diagnostic accuracy of three clinical definitions. Crit Care Med 2005, 33:2228-2234.

6. Rubenfeld GD, Caldwell E, Granton J, Hudson LD, Matthay MA: Interobserver variability in applying a radiographic definition for ARDS. Chest 1999, 116:1347-1353.

7. Soni N: ARDS, acronyms and the Pinocchio effect. Anaesthesia 2010, 65:976-979.

8. Ranieri V, Rubenfeld GD, Thompson B, Ferguson ND, Caldwell E, Fan E, Camporota L, Slutsky AS, Antonelli M, Anzueto A, Beale R, Brochard L, Brower R, Esteban A, Gattinoni L, Rhodes A, Vincent JL, Bersten A, Needham D, Pesenti A: Acute respiratory distress syndrome: the Berlin Definition. JAMA 2012, 307:2526-2533.

9. Rooney SA, Young SL, Mendelson CR: Molecular and cellular processing of lung surfactant. FASEB J 1994, 8:957-967.

10. Lang CJ, Postle AD, Orgeig S, Possmayer F, Bernhard W, Panda AK, Jurgens KD, Milsom WK, Nag K, Daniels CB: Dipalmitoylphosphatidylcholine is not the major surfactant phospholipid species in all mammals. Am J Physiol Regul Integr Comp Physiol 2005, 289:R1426-R1439.

11. Schmidt R, Markart P, Ruppert C, Wygrecka M, Kuchenbuch T, Walmrath D, Seeger W, Guenther A: Time-dependent changes in pulmonary surfactant function and composition in acute respiratory distress syndrome due to pneumonia or aspiration. Respir Res 2007, 8:55.

12. Postle AD, Heeley EL, Wilton DC: A comparison of the molecular species compositions of mammalian lung surfactant phospholipids. Comp Biochem Physiol A Mol Integr Physiol 2001, 129:65-73.

13. Haagsman HP, Diemel RV: Surfactant-associated proteins: functions and structural variation. Comp Biochem Physiol A Mol Integr Physiol 2001, 129:91-108.

14. Petty TL, Silvers GW, Paul GW, Stanford RE: Abnormalities in lung elastic properties and surfactant function in adult respiratory distress syndrome. Chest 1979, 75:571-574

15. Hallman M, Spragg R, Harrell JH, Moser KM, Gluck L: Evidence of lung surfactant abnormality in respiratory failure. Study of bronchoalveolar lavage phospholipids, surface activity, phospholipase activity, and plasma myoinositol. J Clin Invest 1982, 70:673-683.

16. Gregory TJ, Longmore WJ, Moxley MA, Whitsett JA, Reed CR, Fowler AA, 3rd, Hudson LD, Maunder RJ, Crim C, Hyers TM: Surfactant chemical composition and biophysical activity in acute respiratory distress syndrome. J Clin Invest 1991, 88:1976-1981.

17. Gunther A, Siebert C, Schmidt R, Ziegler S, Grimminger F, Yabut M, Temmesfeld B, Walmrath D, Morr H, Seeger W: Surfactant alterations in severe pneumonia, acute respiratory distress syndrome, and cardiogenic lung edema. Am J Respir Crit Care Med 1996, 153:176-184.

18. Nakos G, Kitsiouli El, Tsangaris I, Lekka ME: Bronchoalveolar lavage fluid characteristics of early intermediate and late phases of ARDS. Alterations in leukocytes, proteins, PAF and surfactant components. Intensive Care Med 1998, 24:296-303.

19. Pison U, Seeger W, Buchhorn R, Joka T, Brand M, Obertacke U, Neuhof H, Schmit-Neuerburg KP: Surfactant abnormalities in patients with respiratory failure after multiple trauma. Am Rev Respir Dis 1989, 140:1033-1039.

20. Schmidt R, Meier U, Yabut-Perez M, Walmrath D, Grimminger F, Seeger W, Gunther A: Alteration of fatty acid profiles in different pulmonary surfactant phospholipids in acute respiratory distress syndrome and severe pneumonia. Am J Respir Crit Care Med 2001, 163:95-100.

21. Mason RJ, Nellenbogen J, Clements JA: Isolation of disaturated phosphatidylcholine with osmium tetroxide. J Lipid Res 1976, 17:281-284

22. Greene KE, Wright JR, Steinberg KP, Ruzinski JT, Caldwell E, Wong WB, Hull W, Whitsett JA, Akino T, Kuroki Y, Nagae H, Hudson LD, Martin TR: Serial changes in surfactant-associated proteins in lung and serum before and after onset of ARDS. Am J Respir Crit Care Med 1999, 160:1843-1850.

23. Veldhuizen RA, Inchley K, Hearn SA, Lewis JF, Possmayer F: Degradation of surfactant-associated protein B (SP-B) during in vitro conversion of large 
to small surfactant aggregates. Biochem J 1993, 295:141-147.

24. Holm BA, Matalon S, Finkelstein JN, Notter RH: Type II pneumocyte changes during hyperoxic lung injury and recovery. J Appl Physiol 1988, 65:2672-2678

25. Lewis JF, Ikegami M, Jobe AH. Altered surfactant function and metabolism in rabbits with acute lung injury. J App/ Physio/ 1990, 69:2303-2310.

26. Postle $A D$, Hunt $A N$ : Dynamic lipidomics with stable isotope labelling J Chromatogr B Analyt Technol Biomed Life Sci 2009, 877:2716-2721.

27. Simonato M, Baritussio A, Ori C, Vedovelli L, Rossi S, Dalla ML, Rizzi S, Carniell VP, Cogo PE: Disaturated-phosphatidylcholine and surfactant protein-B turnover in human acute lung injury and in control patients. Respir Res 2011, 12:36

28. Ware LB, Koyama T, Billheimer DD, Wu W, Bernard GR, Thompson BT, Brower RG, Standiford TJ, Martin TR, Matthay MA; NHLBI ARDS Clinical Trials Network: Prognostic and pathogenetic value of combining clinical and biochemical indices in patients with acute lung injury. Chest 2010, 137:288-296.

29. Holm BA, Wang Z, Notter RH: Multiple mechanisms of lung surfactant inhibition. Pediatr Res 1999, 46:85-93.

30. Gunasekara L, Schoel WM, Schurch S, Amrein MW: A comparative study of mechanisms of surfactant inhibition. Biochim Biophys Acta 2008 1778:433-444

31. Haagsman HP: Oxidative damage of the pulmonary surfactant system. Semin Neonatol 1998, 3:207-217.

32. Rodriguez-Capote K, Manzanares D, Haines T, Possmayer F: Reactive oxygen species inactivation of surfactant involves structural and functional alterations to surfactant proteins SP-B and SP-C. Biophys J 2006, 90:2808-2821

33. Kim DK, Fukuda T, Thompson BT, Cockrill B, Hales C, Bonventre JV: Bronchoalveolar lavage fluid phospholipase $\mathrm{A}_{2}$ activities are increased in human adult respiratory distress syndrome. Am J Physiol 1995, 269:L109-L118.

34. Cockshutt AM, Possmayer F: Lysophosphatidylcholine sensitizes lipid extracts of pulmonary surfactant to inhibition by serum proteins. Biochim Biophys Acta 1991, 1086:63-71.

35. Hite RD, Seeds MC, Jacinto RB, Grier BL, Waite BM, Bass DA: Lysophospholipid and fatty acid inhibition of pulmonary surfactant: non-enzymatic models of phospholipase A, surfactant hydrolysis. Biochim Biophys Acta 2005, 1720:14-21.

36. Nakos G, Kitsiouli E, Hatzidaki E, Koulouras V, Touqui L, Lekka ME: Phospholipases $A_{2}$ and platelet-activating-factor acetylhydrolase in patients with acute respiratory distress syndrome. Crit Care Med 2005, 33:772-779.

37. Fujiwara T, Maeta H, Chida S, Morita T, Watabe Y, Abe T: Artificial surfactant therapy in hyaline-membrane disease. Lancet 1980, 1:55-59.

38. Halliday HL: Surfactants: past, present and future. J Perinatol 2008, 28(Suppl 1):S47-S56.

39. Weg JG, Balk RA, Tharratt RS, Jenkinson SG, Shah JB, Zaccardelli D, Horton J, Pattishall EN: Safety and potential efficacy of an aerosolized surfactant in human sepsis-induced adult respiratory distress syndrome. JAMA 1994, 272:1433-1438.

40. Anzueto A, Baughman RP, Guntupalli KK, Weg JG, Wiedemann HP, Raventos AA, Lemaire F, Long W, Zaccardelli DS, Pattishall EN: Aerosolized surfactant in adults with sepsis-induced acute respiratory distress syndrome. Exosurf Acute Respiratory Distress Syndrome Sepsis Study Group. N Engl J Med 1996, 334:1417-1421.

41. Gregory TJ, Steinberg KP, Spragg R, Gadek JE, Hyers TM, Longmore WJ, Moxley MA, Cai GZ, Hite RD, Smith RM, Hudson LD, Crim C, Newton P, Mitchell BR, Gold AJ: Bovine surfactant therapy for patients with acute respiratory distress syndrome. Am J Respir Crit Care Med 1997, 155:1309-1315.

42. Kesecioglu J, Beale R, Stewart TE, Findlay GP, Rouby JJ, Holzapfel L, Bruins P, Steenken EJ, Jeppesen OK, Lachmann B: Exogenous natural surfactant for treatment of acute lung injury and the acute respiratory distress syndrome. Am J Respir Crit Care Med 2009, 180:989-994.

43. Spragg RG, Lewis JF, Wurst W, Hafner D, Baughman RP, Wewers MD, Marsh Jل Treatment of acute respiratory distress syndrome with recombinant surfactant protein C surfactant. Am J Respir Crit Care Med 2003, 167:1562-1566

44. Spragg RG, Lewis JF, Walmrath HD, Johannigman J, Bellingan G, Laterre PF, Witte MC, Richards GA, Rippin G, Rathgeb F, Häfner D, Taut FJ, Seeger W: Effect of recombinant surfactant protein C-based surfactant on the acute respiratory distress syndrome. N Engl J Med 2004, 351:884-892.
45. Markart P, Reppert C, Wygrecka M, Coaris T, Dahal B, Walmrath D, Harbach H, Wilhelm J, Seeger W, Schmidt R, Guenther A: Patients with ARDS show improvement but not normalisation of alveolar surface activity with surfactant treatment: putative role of neutral lipids. Thorax 2007, 62:588-594.

46. Spragg RG, Taut FJ, Lewis JF, Schenk P, Ruppert C, Dean N, Krell K, Karabinis A Gunther A: Recombinant surfactant protein C-based surfactant for patients with severe direct lung injury. Am J Respir Crit Care Med 2011, 183:1055-1061.

47. Meng H, Sun Y, Lu J, Fu S, Meng Z, Scott M, Li Q: Exogenous surfactant may improve oxygenation but not mortality in adult patients with acute lung injury/acute respiratory distress syndrome: a meta-analysis of 9 clinical trials. J Cardiothorac Vasc Anesth 2012, 26:849-856.

48. Lewis J, McCaig L, Hafner D, Spragg R, Veldhuizen R, Kerr C: Dosing and delivery of a recombinant surfactant in lung-injured adult sheep. Am J Respir Crit Care Med 1999, 159:741-747.

49. Spragg RG, Gilliard N, Richman P, Smith RM, Hite RD, Pappert D, Robertson B, Curstedt T, Strayer D: Acute effects of a single dose of porcine surfactant on patients with the adult respiratory distress syndrome. Chest 1994, 105:195-202.

50. Walmrath D, Grimminger F, Pappert D, Knothe C, Obertacke U, Benzing A, Gunther A, Schmehl T, Leuchte H, Seeger W: Bronchoscopic administration of bovine natural surfactant in ARDS and septic shock: impact on gas exchange and haemodynamics. Eur Respir J 2002, 19:805-810.

51. Gunther A, Schmidt R, Harodt J, Schmehl T, Walmrath D, Ruppert C, Grimminger F, Seeger W: Bronchoscopic administration of bovine natural surfactant in ARDS and septic shock: impact on biophysical and biochemical surfactant properties. Eur Respir J 2002, 19:797-804.

52. Schurch S, Possmayer F, Cheng S, Cockshutt AM: Pulmonary SP-A enhances adsorption and appears to induce surface sorting of lipid extract surfactant. Am J Physiol 1992, 263:L210-L218.

53. Higuchi R, Lewis J, Ikegami M: In vitro conversion of surfactant subtypes is altered in alveolar surfactant isolated from injured lungs. Am Rev Respir Dis 1992, 145:1416-1420.

54. Soll RF: Natural surfactant extract versus synthetic surfactant for neonatal respiratory distress syndrome. Cochrane Database Syst Rev 2000, 2:CD000144.

55. Diemel RV, Walch M, Haagsman HP, Putz G: In vitro and in vivo intrapulmonary distribution of fluorescently labeled surfactant. Crit Care Med 2002, 30:1083-1090.

56. Gattinoni L, Chiumello D, Cressoni M, Valenza F: Pulmonary computed tomography and adult respiratory distress syndrome. Swiss Med Wkly 2005, 135:169-174

57. Cockshutt AM, Weitz J, Possmayer F: Pulmonary surfactant-associated protein $A$ enhances the surface activity of lipid extract surfactant and reverses inhibition by blood proteins in vitro. Biochemistry 1990, 29:8424-8429.

58. Seeger W, Gunther A, Thede C: Differential sensitivity to fibrinogen inhibition of SP-C- vs. SP-B-based surfactants. Am J Physiol 1992 262:L286-L291

59. Notter RH, Schwan AL, Wang Z, Waring AJ: Novel phospholipase-resistant lipid/peptide synthetic lung surfactants. Mini Rev Med Chem 2007, 7:932-944

60. Arbibe L, Koumanov K, Vial D, Rougeot C, Faure G, Havet N, Longacre S, Vargaftig BB, Béréziat G, Voelker DR, Wolf C, Touqui L: Generation of lysophospholipids from surfactant in acute lung injury is mediated by type-II phospholipase $\mathrm{A}_{2}$ and inhibited by a direct surfactant protein $\mathrm{A}$ phospholipase A 2 protein interaction. J Clin Invest 1998, 102:1152-1160.

61. Seeger $W$, Lepper $H$, Wolf $H R$, Neuhof $H$ : Alteration of alveolar surfactant function after exposure to oxidative stress and to oxygenated and native arachidonic acid in vitro. Biochim Biophys Acta 1985, 835:58-67.

62. Gilliard N, Heldt GP, Loredo J, Gasser H, Redl H, Merritt TA, Spragg RG Exposure of the hydrophobic components of porcine lung surfactant to oxidant stress alters surface tension properties. J Clin Invest 1994, 93:2608-2615

63. Domingues MR, Reis A, Domingues P: Mass spectrometry analysis of oxidized phospholipids. Chem Phys Lipids 2008, 156:1-12.

64. Bridges JP, Davis HW, Damodarasamy M, Kuroki Y, Howles G, Hui DY, McCormack FX: Pulmonary surfactant proteins $A$ and $D$ are potent endogenous inhibitors of lipid peroxidation and oxidative cellular injury. J Biol Chem 2000, 275:38848-38855. 
65. Bouhafs RK, Jarstrand C: Effects of antioxidants on surfactant peroxidation by stimulated human polymorphonuclear leukocytes. Free Radic Res 2002, 36:727-734.

66. Carnielli VP, Zimmermann $\sqcup$, Hamvas A, Cogo PE: Pulmonary surfactant kinetics of the newborn infant: novel insights from studies with stable isotopes. J Perinatol 2009, 29(Suppl 2):S29-S37.

67. Bernhard W, Pynn CJ, Jaworski A, Rau GA, Hohlfeld JM, Freihorst J, Poets CF, Stoll D, Postle AD: Mass spectrometric analysis of surfactant metabolism in human volunteers using deuteriated choline. Am J Respir Crit Care Med 2004, 170:54-58. doi:10.1186/cc11512

Cite this article as: Dushianthan $A$, et al:: Clinical review: Exogenous surfactant therapy for acute lung injury/acute respiratory distress syndrome - where do we go from here? Critical Care 2012, 16:238. 